\title{
Asymptomatic Isolated Cervical Tubercular Lymphadenopathy, How to Proceed?: A Case Series
}

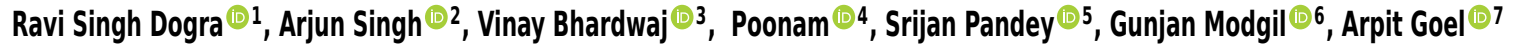 \\ ${ }^{1}$ General Surgeon, Department of Surgery, Civil Hospital Ghumarwin, Bilaspur, Himachal Pradesh, India, ${ }^{2}$ Anesthesiologist, Department of Anesthesia, Civil Hospital \\ Sundarnagar, Mandi, Himachal Pradesh, India, ${ }^{3}$ Physician, Department of Medicine, Civil Hospital Ghumarwin, Bilaspur, Himachal Pradesh, India, ${ }^{4}$ Junior Resident, \\ Department of Anesthesia, Dr. R.P. Govt. Medical College, Tanda, Himachal Pradesh, India, ${ }^{5}$ Junior Resident, Department of Surgery, Dr. R.P. Govt. Medical College, \\ Tanda, Himachal Pradesh, India, 6Junior Resident, Department of Surgery, Dr. R.P. Govt. Medical College, Tanda, Himachal Pradesh, India, ${ }^{7}$ Junior Resident, Department \\ of Surgery, Dr. R.P. Govt. Medical College, Tanda, Himachal Pradesh, India.
}

\section{Abstract}

Tuberculosis is a highly prevalent disease in developing countries, the majority of cases are pulmonary and rest are extra-pulmonary. Cervical LN tuberculosis is one of the most common types of extra-pulmonary tuberculosis. Isolated cervical tubercular Lymphadenitis without accompanying pulmonary tuberculosis or another form of tuberculosis in the body is rare and, when present, requires thorough clinical examination and investigation. In the investigation of such patients, FNAC plays a major role, and aspirate should be tested for AFB through ZN stain and CBNAAT (PCR). Cervical tubercular Lymphadenitis is mainly a disease of young with a female predominance. All patients of cervical tubercular Lymphadenitis must receive antitubercular therapy with strict follow up for compliance and possible side effects from treatment.

Keywords: Extra-pulmonary tuberculosis, Tubercular Cervical Lymphadenitis, FNAC, ZN stain, CBNAAT

Corresponding Author: Arjun Singh, Anesthesiologist, Department of Anesthesia, Civil Hospital Sundarnagar, Mandi, Himachal Pradesh, India. E-mail: dr.arjunthakur@gmail.com

Received: 28 April 2020

Published: 6 July 2020

\section{Introduction}

Tuberculosis is a highly prevalent disease in developing countries. India has high burden of tuberculosis and the average prevalence of all forms of tuberculosis in India is about $5.05 /$ thousand. ${ }^{[1]}$ The majority of cases of tuberculosis are pulmonary, comprising about $80-85 \%$ of cases and rest are extrapulmonary like Lymph node tuberculosis, tubercular pleural effusion, Pot's spine, abdominal tuberculosis and lupus vulgaris. Lymph node Tb (LNT) is a common cause of extra-pulmonary tuberculosis, in areas of the high prevalence of Tuberculosis, LNT is $2^{\text {nd }}$ most common type of extra-pulmonary TB after pleural tuberculosis, and in Low prevalence areas, LNT is a most common type of extrapulmonary tuberculosis. ${ }^{[2-4]}$ Isolated cervical tubercular lymphadenitis/lymphadenopathy is usually rare without evidence of pulmonary tuberculosis or tuberculosis elsewhere in the body.

We are presenting a case series of 7 patients presented to our surgery OPD of referral hospital of the rural area over the period of 6 months from January 2020 to June 2020 with a chief complaint of enlarged $\mathrm{LN}$ in the cervical region without any other symptoms. The majority of these patients were referred cases from their Physician.

Many theories have been proposed regarding the spread of tuberculosis to the Cervical Lymph node (CLN). Kent et al. suggested that Mycobacterium Tuberculosis Spread through Lympho-hematogenous route to CLN from Pulmonary Tuberculosis. ${ }^{[5]}$ Yew et al also suggested that the predominant pathway of the spread of tubercular bacilli from Lung to CLN is through lymphatic as right lung and lower lobe of left lung drain into right smaller cervical LN chain. ${ }^{[6]}$ However, these theories do not explain the pathogenesis of isolated CLN tuberculosis in the absence of pulmonary tuberculosis; therefore, an alternate route of spread to Cervical LN from tonsils and adenoids have been proposed. ${ }^{[7]}$ The demography of CLN tuberculosis is also different compare to pulmonary tuberculosis. CLN tuberculosis is more common in the young age group and female predominance, whereas pulmonary tuberculosis is more common in males and older age groups. ${ }^{[8,9]}$ 


\section{Case Series}

\section{Case 1}

32 year old female presented with a 3-month history of swelling in the right side of the neck with weight loss of about $4 \mathrm{~kg}$ in the last 2-3 months. She had no cough, fever. She had no history of tuberculosis in the past, no contact history with the patient of ATT. She was prescribed multiple courses of Antibiotics at the local hospital, but swelling persisted. The patient was referred to Surgery OPD for evaluation of neck swelling. On examination - she had an LN mass of $3 X 3 \mathrm{~cm}$ on R side of neck; LN was matted to each other, painless, soft and cystic. She was subjected for investigation-

\begin{tabular}{ll}
\hline USG neck & $\begin{array}{l}\text { LN Abscess } \\
\text { ESR }\end{array}$ \\
\hline CXR-PA View & $\begin{array}{l}\text { No evidence of Pulmonary } \\
\text { Tuberculosis }\end{array}$ \\
\hline ZN Stain Sputum & No AFB \\
\hline ZN stain Pus Aspirate & AFB Seen \\
\hline CBNAAT Pus Aspirate & Positive \\
\hline ELISA for HIV & Non-reactive \\
Tuberculin test & $17 \mathrm{~mm}$ \\
\hline
\end{tabular}

\section{Case 2}

A 31-year-old female presented with a 6-month history of multiple cervical swelling with no fever, cough, weight loss, past history does not reveal tuberculosis or contact with the patient on ATT. Took treatment at various places, including traditional medicine. On examination, there was multiple enlarged painless LN of Various size largest $2 \mathrm{X} 3 \mathrm{~cm}$.

\section{Investigations:}

\begin{tabular}{ll}
\hline USG neck & Cervical Lymphadenopathy \\
ESR & $\begin{array}{l}28 \mathrm{~mm} / \mathrm{hr} \\
\text { No evidence of Pulmonary } \\
\text { Tuberculosis }\end{array}$ \\
CXR-PA View & No AFB saw \\
ZN Stain Sputum & No AFB saw \\
ZN stain LN Aspirate & Positive \\
CBNAAT LN Aspirate & Non-reactive \\
ELISA for HIV & 12 mm \\
\hline Tuberculin test & \\
\hline
\end{tabular}

\section{Case 3}

A 21-year-old female came to Surgery OPD with C/o 2 swellings in her posterior side of the neck which she noticed for 1 month. She didn't take any treatment for it initially, but as blisters were persistent for 1 month, she decided to visit the hospital. She had no other complaints like cough, fever, weight loss, loose stool, sore throat. She had no history of TB in the past. On examination- There were two LN of size $1 \mathrm{X} 1$ and $1 \mathrm{X} 2 \mathrm{~cm}$ in the posterior triangle of the neck, they were soft and non-tender.

\begin{tabular}{|c|c|}
\hline USG neck & Cervical Lymphadenopathy \\
\hline ESR & $21 \mathrm{~mm} / \mathrm{hr}$ \\
\hline CXR-PA View & $\begin{array}{l}\text { No evidence of Pulmonary } \\
\text { Tuberculosis }\end{array}$ \\
\hline ZN Stain Sputum & No AFB saw \\
\hline ZN stain LN Aspirate & No AFB seen \\
\hline CBNAAT LN Aspirate & Positive \\
\hline ELISA for HIV & Non reactive \\
\hline Tuberculin test & $15 \mathrm{~mm}$ \\
\hline
\end{tabular}

\section{Case 4}

25 year old female referred from Primary health center with a chief complaint of Painless cervical LAP since 2 months, not responding to empirical antibiotics. She had no constitutional symptoms, no history of tuberculosis in the past and no positive contact history with patients suffering from tuberculosis.

On examination - she had right-sided supraclavicular matted, painless LN mass of size $3 \mathrm{X} 3 \mathrm{~cm}$.

\begin{tabular}{ll}
\hline USG neck & $\begin{array}{l}\text { LN mass at the supraclav- } \\
\text { icular region with abscess } \\
\text { with cervical LAP }\end{array}$ \\
ESR & $55 \mathrm{~mm} / \mathrm{hr}$ \\
CXR-PA View & $\begin{array}{l}\text { No evidence of Pulmonary } \\
\text { Tuberculosis }\end{array}$ \\
ZN Stain Sputum & No AFB seen \\
ZN stain Pus Aspirate & No AFB seen \\
CBNAAT Pus Aspirate & Positive \\
ELISA for HIV & Non-reactive \\
Tuberculin test & 10 mm \\
\hline
\end{tabular}

\section{Case 5}

37 year old female referred from general OPD to Surgery OPD with a diagnosis of cystic cervical swelling at the midline. The patient developed swelling 3months ago with mild pain in it. She visited local Private hospital but the swelling didn't disappear, but the pain disappeared. Then in last 1 month, swelling increases in size and she came to our hospital for further treatment. On examination, there was a soft, cystic, painless swelling in the midline just below the thyroid cartilage, the swelling was not moving with deglutination or tongue protrusion.

\section{Case 6}




\begin{tabular}{ll}
\hline USG neck & $\begin{array}{l}\text { Neck Abscess } \\
\text { ESR }\end{array}$ \\
$\begin{array}{l}38 \mathrm{~mm} / \mathrm{hr} \\
\text { CXR-PA View } \\
\text { Tuberculonis }\end{array}$ \\
\hline ZN Stain Sputum & No AFB saw \\
ZN stain Pus Aspirate & No AFB saw \\
CBNAAT Pus Aspirate & Positive \\
ELISA for HIV & Non-reactive \\
Tuberculin test & $12 \mathrm{~mm}$ \\
\hline
\end{tabular}

A 34-year-old male presented with painless swelling in the posterior side of neck since 6 months with no history of pain, fever, cough, no history of tuberculosis in the past. No treatment history for swelling. On examination, an LN mass of size $2 \mathrm{X} 3 \mathrm{~cm}$ on the posterior triangle on the right side, which was matted, painless, and soft. There were multiple enlarged $\mathrm{LN}$ on the right side of the neck anteriorly.

\begin{tabular}{ll}
\hline USG neck & Cervical LAP \\
ESR & $\begin{array}{l}45 \mathrm{~mm} / \mathrm{hr} \\
\text { No evidence of Pulmonary } \\
\text { Tuberculosis }\end{array}$ \\
\hline CXR-PA View & No AFB saw \\
ZN Stain Sputum & No AFB saw \\
ZN stain LN Aspirate & Positive \\
CBNAAT LN Aspirate & Non-reactive \\
ELISA for HIV & $8 \mathrm{~mm}$ \\
\hline Tuberculin test & \\
\hline
\end{tabular}

\section{Case 7}

A 24-year-old male presented with painless swelling on the left supraclavicular region for 1 month, with no other complaints. No past history of tuberculosis of the patient and his family. On examination- left supraclavicular Lymph node mass of size $2 \times 3 \mathrm{~cm}$, painless, matted and soft.

\begin{tabular}{ll}
\hline USG neck & $\begin{array}{l}\text { Left supraclavicular LN } \\
\text { mass with abscess }\end{array}$ \\
\hline ESR & $\begin{array}{l}32 \mathrm{~mm} / \mathrm{hr} \\
\text { No evidence of Pulmonary } \\
\text { Tuberculosis }\end{array}$ \\
CXR-PA View & No AFB saw \\
\hline ZN Stain Sputum & AFB saw \\
ZN stain Pus Aspirate & Positive \\
\hline CBNAAT Pus Aspirate & Non-reactive \\
ELISA for HIV & $15 \mathrm{~mm}$ \\
\hline Tuberculin Test & \\
\hline
\end{tabular}

\section{Discussion}

In surgical practice all surgeons get encounter with patients with Cervical Lymphadenopathy and the majority of these patients are referred patients from their primary Physician. The differential diagnosis for CLN mass includes infectious like tonsillitis, mumps, CMV, tuberculosis, brucellosis, Staphylococcal Lymphadenitis, Human immunodeficiency virus, Infectious mononucleosis, toxoplasmosis, and malignant causes include- lymphoma, leukemia, oral cavity cancer, thyroid cancer, metastatic lymphadenopathy like Virchow's LN. Because of a variety of differential diagnoses of Cervical Lymphadenopathy, it is sometimes challenging to make a diagnosis. In the differential diagnosis of Cervical LN Mass, Cervical Tubercular Lymphadenitis should be kept in mind, especially in endemic areas like India. The patient may present as Single Large LN to Multiple LAP mostly, matted and located in the posterior triangle or in supraclavicular region. ${ }^{[10]}$ Most of these patients have a long history of LAP and some even present as pus discharging sinus after ruptured cold abscess. ${ }^{[11,12]}$ Unlike pulmonary tuberculosis, constitutional symptoms like wt loss, night sweat, wt loss occurs variably in patients of CTL. ${ }^{[13]}$ About 20-40 percent of patients with CTL also have accompanying pulmonary tuberculosis; hence each patient should be tested for pulmonary tuberculosis. ${ }^{[14]}$ Making a diagnosis in such patients requires a variety of investigations like - ESR, ELISA for HIV, Sputum for ZN Stain, pus For ZN Stain, tuberculin Skin test, CXR, USG/CT Neck, FNAC of LN for ZN stain, PCR (CBNAAT) and culture for mycobacterium and sometime LN biopsy for HPE when the diagnosis is uncertain or there is diagnosis dilemma. Elevated ESR suggests an ongoing inflammatory process in the body and is usually elevated in tuberculosis, ZN stain is used to demonstrate acid-fast bacilli in different body samples it is rapid and cheap with $100 \%$ specificity and sensitivity ranges between $46 \%-78 \%$ depending upon sample source. ${ }^{[15]}$ Tadesse et al revealed that higher the Concentration of aspirate material greater the yield of $\mathrm{Zn}$ staining for AFB. ${ }^{[16]} \mathrm{A}$ tuberculin skin test is done to demonstrate delayed-type hypersensitivity to tubercular bacilli. Chest x-ray (CXR) helps to make a diagnosis of accompanying pulmonary TB. Imaging of neck like USG/ CT helps to find necrosis, pus in LN. FNAC of Lymph node must be done and aspirate must be tested for AFB by ZN stain, and PCR/CBNAAT (sensitivity and specificity for needle aspirate is $71.4 \%$ to $92.1 \%$ ). ${ }^{[17,18]}$ Though mycobacterium culture is most sensitive and specific but it is seldom done due to the long incubation period of bacteria.

We subjected our patients for ESR, Tuberculin Skin test, CXR, USG neck, ZN stain for sputum and Pus/ aspirate from LN, CBNAAT of Aspirate/pus. In all of our cases, no evidence of pulmonary or extra-pulmonary tuberculosis was found apart from cervical tubercular Lymphadenitis. CBNAAT of LN aspirate was positive for AFB in all 7 cases, whereas the 

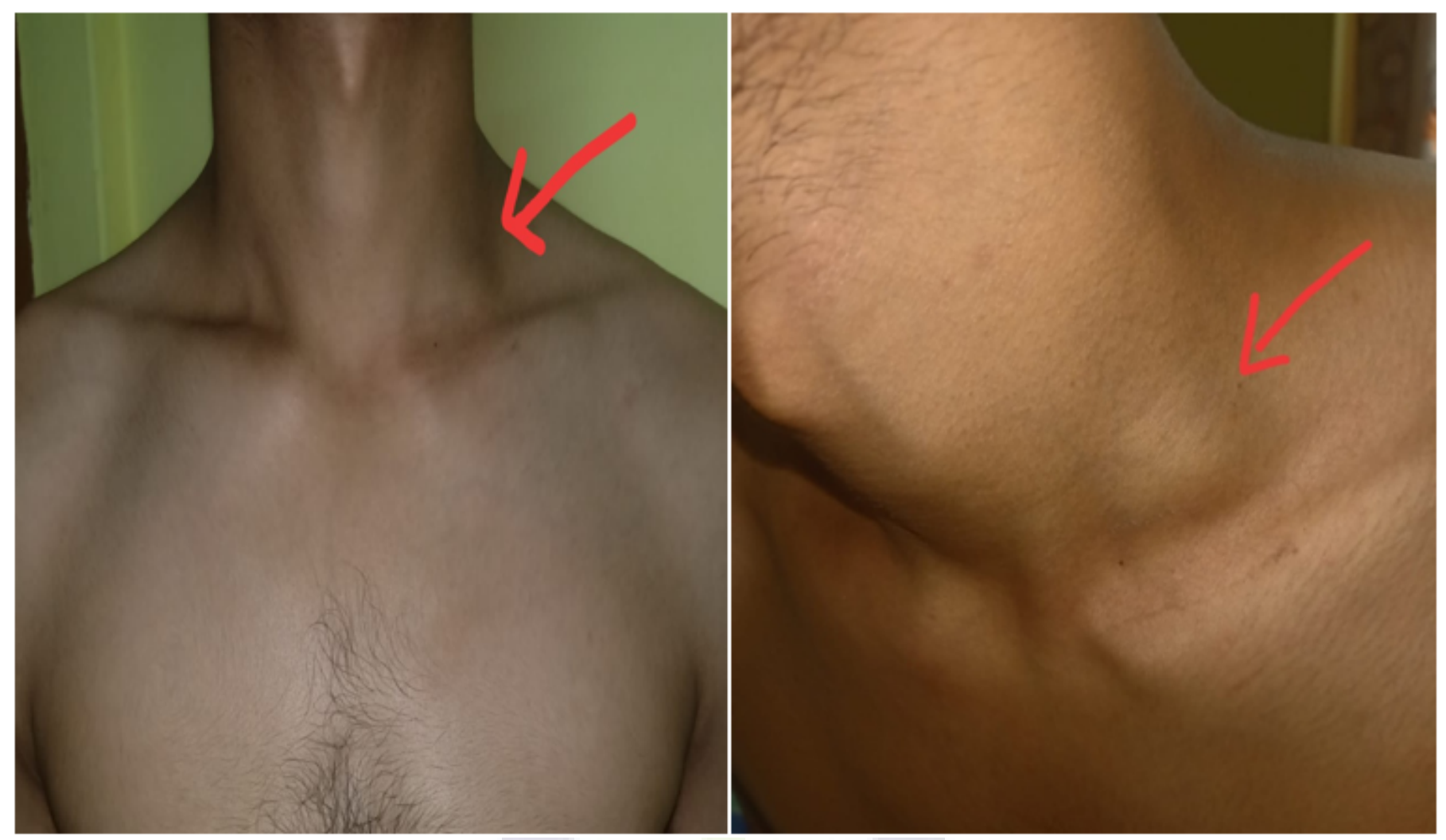

Figure 1: Showing Left Supraclavicular LN mass in AP and Lateral view, respectively.

ZN stain of $\mathrm{LN}$ aspirates was positive for AFB in only 2 cases. All 7 patients were young and only one patient had constitutional symptoms and 5 out of 7 were female patients. None of these patients had a previous history of tuberculosis. We started all 7 patients on the Fixed Dose Combination (FDC) regime for tuberculosis as per the guidelines of RNTCP. All 7 patients were registered under RNTCP for followup. Out of 7 patients, 1 patient developed skin rashes after taking antitubercular drugs (Ethambutol induced) and her ATT regimen was changed after taking Dermatology consultation.

\section{Conclusion}

Cervical tubercular Lymadenitis/ lymphadenopathy is a potential differential diagnosis for isolated cervical LN mass, and it should be in our mind while treating patients with cervical lymphadenopathy. All such patients must be started on antitubercular therapy and there follow up should be kept for possible side effects and for compliance to prevent MDR tuberculosis.

\section{References}

1. Chakraborty AK. Epidemiology of tuberculosis: current status in India. Indian J Med Res. 2004;120(4):248-276.
2. Tatar D, Senol G, Alptekin S, Gunes E. Assessment of Lymph node tuberculosis in two provinces in Turkey. Jpn J Infect Dis. 2011;64(4):316-321.

3. Golden MP, Vikram HR. Extra-pulmonary tuberculosis: an overview. Am Fam Physician. 2005;72(9):1761-1768.

4. Yesuf KM, Berhie KA, Yesuf JS, Atsedeweyn A, Abegaz ST. Analysis of Survival and Associated Risk Factors among HIV/AIDS Patients Who Started Antiretroviral Therapy (ART) in Central, Western and North Gondar Zones, North West Ethiopia. Asian J Med Res. 2018;7(3):7-12. Available from: https://dx.doi.org/10.21276/ajmr.2018.7.3.CM2.

5. Kent DC. Tuberculosis lymphadenitis: not a localized disease process. Am J Med Sci. 1967;254:866-74.

6. Yew WW, Lee J. Pathogenesis of cervical tuberculous Lymphadenitis: pathways to anatomic localization. Tuber Lung Dis. 1995; 76:275-281.

7. Selimo $\square$ lu E, Sütbeyaz Y, Çiftçio $\square$ lu MA, Parlak M, Esrefo $\square$ lu M, Öztürk A. Primary tonsillar tuberculosis: a case report. The Journal of Laryngology \& Otology. 1995;109(9):880-882. Available from: https://dx.doi.org/10. 1017/s0022215100131573. doi:10.1017/s0022215100131573.

8. Jha BC, Dass A, Nagarkar NM, Gupta R, Singhal S. Cervical tuberculous lymphadenopathy:changing clinical pattern and concepts in management. Postgrad Med J. 2001;77:185-192. 
9. Geldmacher H, Taube C, Kroeger C, Magnussen H, Kirsten DK. Assessment of Lymph Node Tuberculosis in Northern Germany. Chest. 2002;121(4):1177-1182. Available from: https://dx.doi.org/10.1378/chest.121.4.1177.

10. Penfold CN, Penfold CN. A review of 23 patients with tuberculosis of the head and neck. Br J Oral Maxillofacial Surg. 1996;34(6):508-510. Available from: https://doi.org/10.1016/ S0266-4356(96)90246-6.

11. Polesky A, Grove W, Bhatia G. Peripheral tuberculous lymphadenitis:epidemiology, diagnosis, treatment, and outcome. Medicine (Baltimore). 2005;84:350-62.

12. Konishi K, Yamane H, Iguchi H, Nakagawa $T$, Shibata S, Takayama M. Study of tuberculosis in the field of Otorhinolaryngology in the past 10 years. Acta Otolaryngol Suppl. 1998;598:244-253.

13. Dandapat MC, Mishra BM, Dash SP, Kar PK. Peripheral lymph node tuberculosis: A review of 80 cases. Br J Surg. 1990;77(8):911-912. Available from: https://dx.doi.org/10. 1002/bjs.1800770823.

14. Shriner KA, Mathisen GE, Goetz MB. Comparison of Mycobacterial Lymphadenitis Among Persons Infected with Human Immunodeficiency Virus and Seronegative Controls. Clin Inf Dis. 1992;15(4):601-605. Available from: https://dx. doi.org/10.1093/clind/15.4.601.

15. Mittal P, Handa U, Mohan H, Gupta V. Comparative evaluation of fine needle aspiration cytology, culture, and PCR in diagnosis of tuberculous lymphadenitis. Diag Cytopathol. 2011;39(11):822-826. Available from: https://dx.doi.org/10. $1002 /$ dc. 21472.
16. Tadesse M, Abebe G, Abdissa K, Bekele A, Bezabih M, Apers $\mathrm{L}$, et al. Concentration of Lymph Node Aspirate Improves the Sensitivity of Acid Fast Smear Microscopy for the Diagnosis of Tuberculous Lymphadenitis in Jimma, Southwest Ethiopia. PLoS One. 2014;9(9):e106726. Available from: https://dx.doi. org/10.1371/journal.pone.0106726.

17. Baek CH, Kim SI, Ko YH, Chu KC. Polymerase chain reaction detection of Mycobacterium tuberculosis from fineneedle aspirate for the diagnosis of cervical tuberculous Lymphadenitis. Laryngoscope. 2000;110:30-34.

18. Estomba CMC, Reinoso FAB, Schmitz TR, Echeverri CCO, Cortés MJG, Hidalgo CS. Head and Neck Tuberculosis: 6-Year Retrospective Study. Acta Otorrinolaringol. 2016;67(1):914. Available from: https://dx.doi.org/10.1016/j.otoeng.2014. 11.006.

Copyright: (C) the author(s), 2020. It is an open-access article distributed under the terms of the Creative Commons Attribution License (CC BY 4.0), which permits authors to retain ownership of the copyright for their content, and allow anyone to download, reuse, reprint, modify, distribute and/or copy the content as long as the original authors and source are cited.

How to cite this article: Dogra RS, Singh A, Bhardwaj V, Poonam , Pandey S, Modgil G, Goel A. Asymptomatic Isolated Cervical Tubercular Lymphadenopathy, How to Proceed?: A Case Series. Asian J. Med. Res. 2020;9(2):1-5.

DOI: dx.doi.org/10.47009/ajmr.2020.9.2.SG1

Source of Support: Nil, Conflict of Interest: None declared. 